\title{
FSH isoform pattern in classic galactosemia
}

\author{
Cynthia S. Gubbels • Chris M. G. Thomas • Will K. W. H. Wodzig • André J. Olthaar • \\ Jaak Jaeken • Fred C. G. J. Sweep • M. Estela Rubio-Gozalbo
}

Received: 19 May 2010 /Revised: 19 May 2010/Accepted: 19 July 2010 / Published online: 3 September 2010

(C) The Author(s) 2010. This article is published with open access at Springerlink.com

\begin{abstract}
Female classic galactosemia patients suffer from primary ovarian insufficiency (POI). The cause for this long-term complication is not fully understood. One of the proposed mechanisms is that hypoglycosylation of complex molecules, a known secondary phenomenon of galactosemia, leads to FSH dysfunction. An earlier study showed less acidic isoforms of FSH in serum samples of two classic galactosemia patients compared to controls, indicating hypoglycosylation. In this study, FSH isoform patterns of five classic galactosemia patients with POI were compared to the pattern obtained in two patients with a primary glycosylation disorder (phosphomannomutase-2-deficient congenital disorders of glycosylation, PMM2-CDG) and POI, and in five postmenopausal women as controls. We used FPLC chromatofocussing with measurement of FSH
\end{abstract}

Communicated by: Gerard T. Berry

Competing interest: None declared.

C. S. Gubbels

Department of Pediatrics, Maastricht University Medical Center,

Maastricht, The Netherlands

C. M. G. Thomas

Laboratory of Genetic, Endocrine and Metabolic Diseases,

Department of Laboratory Medicine and Department of Obstetrics and Gynaecology, Radboud University Nijmegen Medical Centre,

Nijmegen, The Netherlands

W. K. W. H. Wodzig

Department of Clinical Chemistry,

Maastricht University Medical Center,

Maastricht, The Netherlands

\section{A. J. Olthaar}

Laboratory of Genetic, Endocrine and Metabolic Diseases,

Department of Laboratory Medicine,

Radboud University Nijmegen Medical Centre,

Nijmegen, The Netherlands concentration per fraction, and discovered that there were no significant differences between galactosemia patients, PMM2-CDG patients and postmenopausal controls. Our results do not support that FSH dysfunction due to a less acidic isoform pattern because of hypoglycosylation is a key mechanism of POI in this disease.

\section{Introduction}

Classic galactosemia (OMIM 230400), an inherited metabolic disorder in galactose metabolism due to a deficiency of galactose-1-phosphate uridyl transferase (GALT), is known to cause glycosylation abnormalities (Charlwood et al 1998; Dobbie et al 1990; Haberland et al 1971; Jaeken et al 1992;

\footnotetext{
J. Jaeken

Center for Metabolic Disease, University Hospital Gasthuisberg, Leuven, Belgium
}

F. C. G. J. Sweep

Laboratory of Genetic, Endocrine and Metabolic Diseases,

Department of Laboratory Medicine,

Radboud University Nijmegen Medical Centre,

Nijmegen, The Netherlands

\section{E. Rubio-Gozalbo $(\bowtie)$}

Department of Pediatrics and Laboratory of Inherited Metabolic Diseases, Maastricht University Medical Center, P.O. Box 5800, 6202 AZ Maastricht, The Netherlands e-mail: estela.rubio@mumc.nl 
Ornstein et al 1992; Petry et al 1991; Prestoz et al 1997; Stibler et al 1997; Sturiale et al 2005). Under a galactoserestricted diet, these abnormalities diminish but do not completely disappear (Charlwood et al 1998). Two main mechanisms to explain the aberrant glycosylation have been proposed. Classic galactosemia patients have a low UDPgalactose/UDP-glucose ratio ( $\mathrm{Ng}$ et al 1989), which may influence glycoprotein and glycolipid glycan synthesis. Furthermore, galactose-1-phosphate (Gal-1-P), one of the metabolites that accumulates in classic galactosemia, can inhibit galactosyltransferases and disturb glycosylation (Lai et al 2003).

Abnormal glycosylation of FSH has been proposed as a key mechanism in the development of primary ovarian insufficiency (POI), one of the most prevalent and burdensome long-term complications in galactosemic women. Prestoz et al (1997) detected altered, less acidic isoforms of FSH between pH 6.4 and 7.0 in three women with classic galactosemia when compared to healthy premenopausal women. The idea that glycosylation abnormalities of FSH play a role in POI in galactosemia is further supported by the fact that women with a phosphomannomutase 2-deficient congenital disorder of glycosylation (PMM2-CDG) also have similar early age onset hypergonadotropic hypogonadic ovarian failure (de Zegher and Jaeken 1995; Kristiansson et al 1995). Electrophoretic isoform patterns of FSH in CDG, however, showed normal, acidic FSH (Kristiansson et al 1995), and bioactivity was low-normal (de Zegher and Jaeken 1995).

In the present study, we compared the serum FSH isoform patterns of five classic galactosemia patients with POI with those of two PMM2-CDG patients and five healthy postmenopausal controls.

\section{Patients and methods}

\section{Patients}

Blood samples from five galactosemia patients (aged between 21 and 26 years) and two PMM2-CDG patients (both aged 33 years) with hypergonadotropic hypogonadism and five postmenopausal women (aged 45-68 years) were obtained under standard conditions, and serum was kept frozen at $-80^{\circ} \mathrm{C}$ until assayed. All women were diagnosed with ovarian insufficiency by FSH measurements ( $>30 \mathrm{IU} / \mathrm{l})$ and clinical features (amenorrhea). The women used no medication at the time of blood withdrawal (hormone replacement therapy, if used, was stopped for at least 7 consecutive days before blood withdrawal). Because both galactosemia patients and PMM2-CDG patients with POI have biochemical (i.e. hypergonadotropic- hypoestrogenic) postmenopausal-like features, we decided to use serum of postmenopausal women as controls. The institutional review board of Maastricht University Medical Center approved the protocol as part of a larger study, and the protocol is in accordance with the Declaration of Helsinki. After oral and written information about the study design and protocol, the patients signed an informed consent for this study.

\section{Methods}

We studied chromatofocusing isoform distribution patterns of FSH according to its net charge. The analytical procedure and the consecutive statistical analysis was described in detail by Thomas et al. (2009). Instead of $2.5 \mathrm{~mL}$ serum, we used $0.5 \mathrm{~mL}$ serum for the present procedure. Samples and buffers were prepared as described previously, and an Äkta FPLC system (GE Healthcare) was equipped with a 4-mL Mono-P $5 / 200 \mathrm{GL}$ column and equilibrated with $40 \mathrm{~mL}$ of startbuffer (i.e., bis(2-hydroxyethyl)imino-tris(hydroxymethyl)methane; bis-tris, 7.14 mM, pH 7.3-7.4). A pH gradient was generated by introduction of elution buffer (Polybuffer 74; GE Healthcare Biosciences, Uppsala, Sweden) used at a dilution of 1:35, $\mathrm{pH}$ 3.2 at a flow rate of $1.0 \mathrm{~mL}$ per min. After collection of 70 consecutive $2-\mathrm{mL}$ effluent fractions in tubes containing $50 \mu \mathrm{L}$ of $0.8 \mathrm{M}$ phosphate buffer in $0.15 \mathrm{M} \mathrm{NaCl}$ with $0.2 \% \mathrm{NaN} 3(\mathrm{pH} 7.4)$, the $\mathrm{pH}$ was 3.2. In every fifth tube not containing phosphate buffer, the $\mathrm{pH}$ was measured manually with a pH meter (Metrohm 744; Metrohm, Herisau, Switserland). To increase sensitivity, all the collected fractions were concentrated 10-fold by evaporating them under nitrogen gas at $30^{\circ} \mathrm{C}$ overnight. Subsequently, the dried fractions were reconstituted in $0.2 \mathrm{ml}$ ultra pure water (Elga Ultra Pure Water System, High Wycombe, UK) and the FSH concentrations in all individual effluent fractions were determined with the random access analyser Architect (Abbott, Chicago, IL, USA). The measured FSH concentrations in all collected effluent $\mathrm{pH}$ fractions were corrected for procedural losses by taking the quantity of FSH loaded onto the Mono-P column as $100 \%$. From these corrected data, we calculated the relative amounts of $\mathrm{FSH}$ at fixed $\mathrm{pH}$ values of $\mathrm{pH} 7.0,6.9,6.8, \ldots$, to $\mathrm{pH} 3.0$ by interpolation. In order to test the largest discriminatory capacity between the five galactosemia patients and the two PMM2-CDG patients with hypergonadotropic hypogonadism and the five postmenopausal women, we determined with Student's $t$ tests in Excel 2007 for which $\mathrm{pH}$ interval (i.e., the sum of the relative amounts of FSH present in several consecutive fixed $\mathrm{pH}$ fractions), the difference between the sums of the FSH amounts in the various groups, was largest. In addition, we calculated the mean, median and peak values (defined as the $\mathrm{pH}$ interval in which the highest percentage of FSH was found) for each group from the experimental values and compared the obtained values using SPSS 16.0. 


\section{Results}

Figure 1 shows the average isoform pattern of each group. It was constructed by calculating the mean value for every interpolated $\mathrm{pH}$ interval per group. We did not find significant levels of FSH isoforms in the $\mathrm{pH}$ 5.5-7.0 region. Statistical comparison of the means, medians and peak values between the galactosemia patients, CDG patients and control subjects did not show significant differences. When comparing the groups per $\mathrm{pH}$ interval, the CDG patients differed slightly from the classic galactosemia patients and the controls in the acidic region $(\mathrm{pH}<4.5)$, but this might be caused by the small number of CDG-PMM2 patients in this study. The classic galactosemia patients did not significantly differ from the control patients.

\section{Discussion}

Although some small differences between the groups are seen, we did not find a significantly altered distribution of FSH isoforms when comparing galactosemia patients, PMM2-CDG patients and healthy postmenopausal controls. The majority of FSH had a pH between 3.3 and 5.0 in all three groups, and we did not find a significant amount of FSH isoforms with $6.0 \leq \mathrm{pH}<7.0$. FSH consists of two subunits, alpha and beta. The alpha subunit is identical to that of three other glycoprotein hormones ( $\mathrm{LH}, \mathrm{hCG}$ and TSH) and has two glycosylation sites that probably do not contribute to bioactivity while half-life differences between isoforms are due to compensatory mechanisms in the beta subunit glycans. The human beta subunit has two glycosylation sites, at $\mathrm{Asn}^{7}$ and $\mathrm{Asn}^{24}$, and the most common glycans have terminal sialic acid (Dalpathado et al 2006). If glycans are truncated, sialic acid is missing at the end, resulting in less acidic isoforms. The observed lack of FSHisoforms with a $\mathrm{pH}$ between 6.0 and 7.0 differs from previous results (Prestoz et al 1997). In that study, a large band of FSH in the range of $\mathrm{pH} 6.4-7.0$ on isoelectric focussing was found. The other FSH-bands observed by this group, between $\mathrm{pH} 3.7$ and 4.4, are in accordance with our findings, as almost all the FSH we measured was recovered in the $\mathrm{pH}$ interval between 3.3 and 5.0.

The normally appearing, postmenopausal-like FSH isoform patterns do not favour FSH dysfunction due to hypoglycosylation as a mechanism in the pathophysiology of ovarian failure in classic galactosemia. This is further supported by the finding of a similar FSH-isoform pattern in the two PMM2-CDG patients, and by an earlier report that shows that $\mathrm{CDG}$ patients have acidic isoforms rather than more basic isoforms (Kristiansson et al 1995).

Moreover, a normal FSH bioactivity in classic galactosemic women (Kaufman et al 1981; Sanders et al 2008) has been reported. The reported pregnancy following recombinant FSH administration in a galactosemic woman (Menezo et al 2004) is likely not due to rFSH overruling the inactive endogenous FSH, but merely the stimulation of an insufficiently functioning ovary by a surplus of FSH.

In conclusion, classic galactosemic women with POI have an FSH isoform pattern resembling that of postmenopausal women. Our results do not support that FSH dysfunction due to an abnormal FSH-isoform pattern as a
Fig. 1 Average FSH isoform distribution pattern of classic galactosemia patients $(n=5)$ compared to PMM2-CDG patients $(n=2)$ and postmenopausal controls $(n=5)$

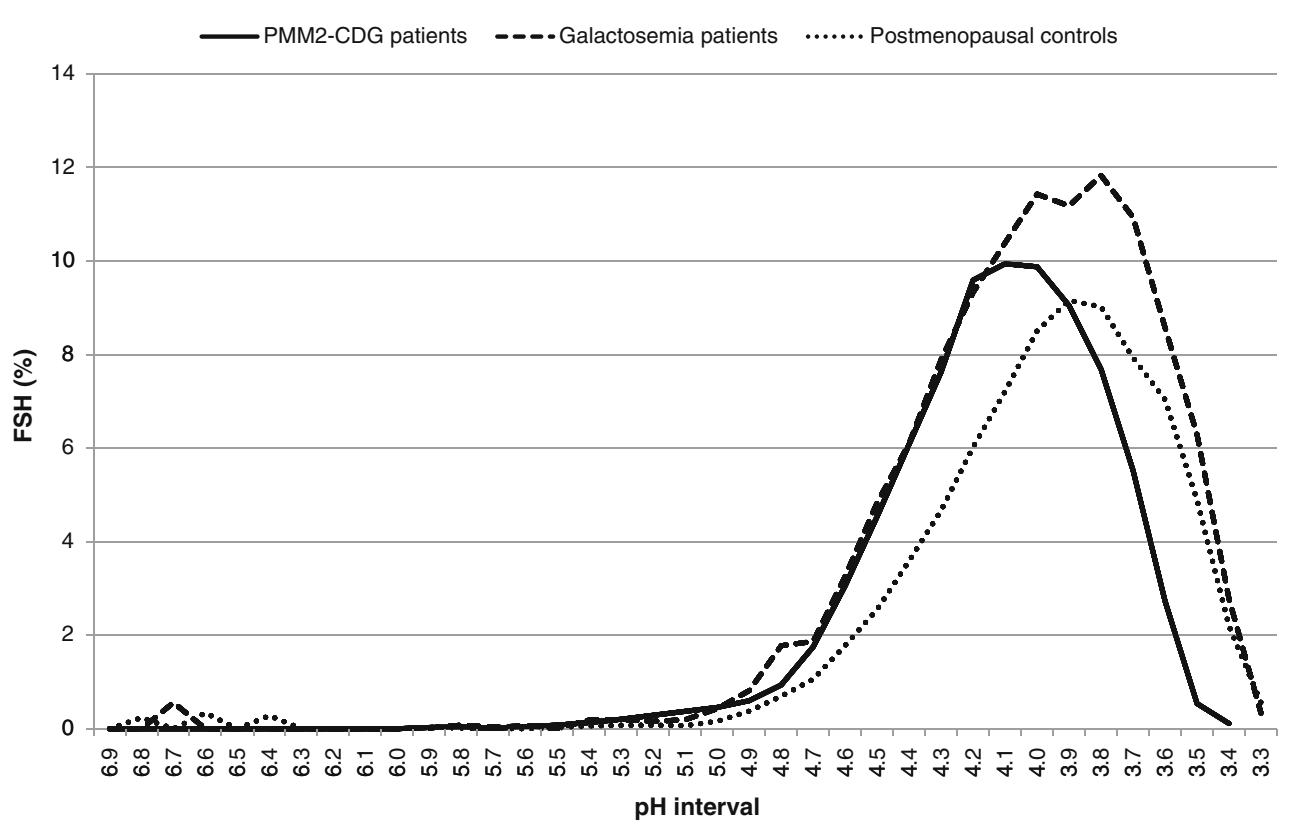


result of hypoglycosylation is a key mechanism of POI in classic galactosemia. Future research should focus on other pathophysiological mechanisms underlying primary ovarian insufficiency in classic galactosemia.

Details of funding This study was funded by the 'Profileringsfonds academisch ziekenhuis Maastricht' and the Dutch Galactosemia Society (GVN). The authors confirm independence from the sponsors; the content of the article has not been influenced by the sponsor

Financial support This study was supported financially by 'Profileringsfonds azM' (research foundation of Maastricht University Medical Center) and 'Galactosemie Onderzoek Fonds' (Galactosemia research foundation of the Netherlands).

Open Access This article is distributed under the terms of the Creative Commons Attribution Noncommercial License which permits any noncommercial use, distribution, and reproduction in any medium, provided the original author(s) and source are credited.

\section{References}

Charlwood J, Clayton P, Keir G, Mian N, Winchester B (1998) Defective galactosylation of serum transferrin in galactosemia. Glycobiology 8(4):351-357

Dalpathado DS, Irungu J, Go EP et al. (2006) Comparative glycomics of the glycoprotein follicle stimulating hormone: glycopeptide analysis of isolates from two mammalian species. Biochemistry 45(28):8665-8673

de Zegher F, Jaeken J (1995) Endocrinology of the carbohydratedeficient glycoprotein syndrome type 1 from birth through adolescence. Pediatr Res 37(4 Pt 1):395-401

Dobbie JA, Holton JB, Clamp JR (1990) Defective galactosylation of proteins in cultured skin fibroblasts from galactosaemic patients. Ann Clin Biochem 27(Pt 3):274-275

Haberland C, Perou M, Brunngraber EG, Hof H (1971) The neuropathology of galactosemia. A histopathological and biochemical study. J Neuropathol Exp Neurol 30(3):431-447
Jaeken J, Kint J, Spaapen L (1992) Serum lysosomal enzyme abnormalities in galactosaemia. Lancet 340(8833):1472-1473

Kaufman FR, Kogut MD, Donnell GN, Goebelsmann U, March C, Koch R (1981) Hypergonadotropic hypogonadism in female patients with galactosemia. N Engl J Med 304 (17):994-998

Kristiansson B, Stibler H, Wide L (1995) Gonadal function and glycoprotein hormones in the carbohydrate-deficient glycoprotein (CDG) syndrome. Acta Paediatr 84(6):655-659

Lai K, Langley SD, Khwaja FW, Schmitt EW, Elsas LJ (2003) GALT deficiency causes UDP-hexose deficit in human galactosemic cells. Glycobiology 13(4):285-294

Menezo YJ, Lescaille M, Nicollet B, Servy EJ (2004) Pregnancy and delivery after stimulation with $\mathrm{rFSH}$ of a galatosemia patient suffering hypergonadotropic hypogonadism: case report. J Assist Reprod Genet 21(3):89-90

Ng WG, Xu YK, Kaufman FR, Donnell GN (1989) Deficit of uridine diphosphate galactose in galactosaemia. J Inherit Metab Dis 12 (3):257-266

Ornstein KS, McGuire EJ, Berry GT, Roth S, Segal S (1992) Abnormal galactosylation of complex carbohydrates in cultured fibroblasts from patients with galactose-1-phosphate uridyltransferase deficiency. Pediatr Res 31(5):508-511

Petry K, Greinix HT, Nudelman E et al (1991) Characterization of a novel biochemical abnormality in galactosemia: deficiency of glycolipids containing galactose or $\mathrm{N}$-acetylgalactosamine and accumulation of precursors in brain and lymphocytes. Biochem Med Metab Biol 46(1):93-104

Prestoz LL, Couto AS, Shin YS, Petry KG (1997) Altered follicle stimulating hormone isoforms in female galactosaemia patients. Eur J Pediatr 156(2):116-120

Sanders RD, Spencer JB, Epstein MP et al (2008) Biomarkers of ovarian function in girls and women with classic galactosemia. Fertil Steril doi:10.1016/j.fertnstert.2008.04.060

Stibler H, von Döbeln U, Kristiansson B, Guthenberg C (1997) Carbohydrate-deficient transferrin in galactosaemia. Acta Paediatr 86(12): 1377-1378

Sturiale L, Barone R, Fiumara A et al (2005) Hypoglycosylation with increased fucosylation and branching of serum transferrin $\mathrm{N}$-glycans in untreated galactosemia. Glycobiology 15(12):12681276

Thomas CMG, Span PN, Smeenk JMJ, Hanssen RGJM, Braat DDM, Sweep FCGJ (2009) Occurrence of postmenopausal-like acidic follicle-stimulating hormone (FSH) isoforms precedes the rise of FSH before menopause. Fertil Steril 92(2):613-619 